\title{
25 Exploring a Dynamic Role for Water in Agriculture
}

\author{
Simon Charter \\ UK branch of the Natural Science Section at the Goetheanum, Switzerland \\ Ebb and Flow Ltd, UK
}

\section{CONTENTS}

Introduction.

Phenomenological and Epistemological Background: The Union of Sense Experience

(Percepts) and Ideas (Concepts) as the Basis of Knowledge.

Geometry and Gestures in Flow: Spiral and Ring Vortices

Rhythm - Another Gesture of Flow

The Dynamisation of Water ......

Flowform Movement: An Alternative Method of Dynamisation ............................................ 287

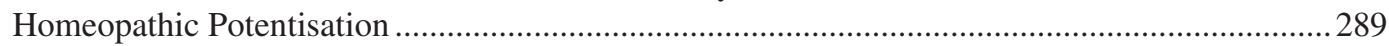

Concluding Discussion: Research with the Life-Forming Forces ............................................290

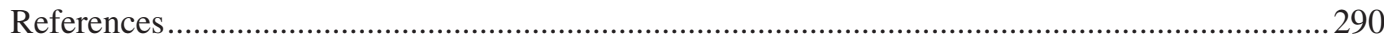

\section{INTRODUCTION}

This chapter is concerned with the healthy 'forming' of living organisms (their form development to maturity) and the ways this may be enhanced with methods that involve water. Few can really claim to have the full picture when it comes to understanding how plants and animals emerge into life, form themselves, grow and develop healthily. Within many traditional worldviews as well as some modern ones, there are believed to be subtle forces at work which organise life's functions, and these are variously termed pranha, chi or the etheric. In my own practice with reed bed systems, water cleaning ecologies and landscapes with moving water, I noticed plants, and especially, flowers have better-developed forms when growing in certain situations rather than others. Having heard about life's formative forces through working on a biodynamic farm and having learnt how projective geometry reveals principles found in natural forms, I found myself researching the relationships between qualities of form in water flow and the forming of life. Such work was pioneered by Theodor Schwenk (2014) in the 1950s. This chapter provides aspects of the results of that research, much of which has been collaborative.

The chapter explores the principles of form that are found in geometry, in the realm of pure idea and relates these to the observed flow movements, or gestures, in the realm of pure perception. It does not seek to justify any particular worldview, but the intention is to allow the relationships between the ideas and the observations to reveal what is at work.

Biodynamic agriculturalists and others are interested in strengthening the working of the forming principles, the formative forces within living organisms, in order to engender health in the farm ecology. Such forces are associated with the moon, the sun and the planets, and their positions and movements in relation to the earth and the stars. Water is seen to mediate these forces and influences, so one may enhance them by working with water. This chapter aims to build an understanding of water by examining the way water flows naturally and seeking the inherent principles in this. It begins by discussing the epistemological basis for this work, how, through taking a Goethean 
approach, we can become more confident in our understanding. It then builds a picture of water flow by showing three distinct 'movement gestures' which interplay and can also be seen in life forms. These gestures can be experienced in a qualitative, artistic way, as with dramatic or sculptural gestures, but can also be defined geometrically and drawn simply but precisely through the interplay of points and lines. This provides a background to then look at the practice of 'dynamisation', the 'enlivening' of water by inducing particular movements, as well as other ways of moving water used in some agricultural practice. It examines the water movements in specifically designed vessels (Flowforms) as well as those in potentisation. The chapter concludes with a consideration of possible connections between the researcher and research results when investigating organic life.

\section{PHENOMENOLOGICAL AND EPISTEMOLOGICAL BACKGROUND: THE UNION OF SENSE EXPERIENCE (PERCEPTS) AND IDEAS (CONCEPTS) AS THE BASIS OF KNOWLEDGE}

If we wish to develop any clear and useful knowledge, we need to find appropriate concepts with which to meet the things we can experience with our senses. We judge our understanding by the degree to which the concepts make sense of the perceived phenomena, by the degree they create a satisfying meaning of our experience. Some concepts make meaning for a single occurrence only, while others, we realise, apply widely. If we can see an active principle to be at work in all instances, we may call it an archetypal idea. These archetypal ideas give us the greatest meaning, since we see the instances related to a wholeness, we see the principles of the whole at work in the parts.

Taking a monistic perspective, I see both our ideas and the sense percept as being united within the world we encounter. It is only in our minds that they are separate. This view comes to light in the works of J. W. von Goethe and was clarified by Rudolf Steiner (Seamon and Zajonc, 1998; Steiner, 1988). It has been expressed more recently by Gregory Bateson and Henri Bortoft (Bateson, 2002; Bortoft, 1996, 2012). Through the practice of science stemming from Goethe (termed Goethean inquiry, or Goethean phenomenology), we can gain moments of direct understanding, when it is possible to 'see' that the idea is one with the percept, to 'realise' an organising principle at work in the object of study as one perceives it (Colquhoun and Ewald, 1996; Hoffman, 2007; Holdrege, 2013). Once this has happened, the idea is always there, and it can be shared with others who may take it on intellectually or 'realise' the truth of it themselves. It is this quality of understanding which occurs in 'A-ha moments' or 'Eureka' experiences, which are the subject of neurological research (Danek and Salvi, 2020).

With water in flow, however, the organising principles are found to be flexible ideas that we can grasp but never entirely possess (Holdrege, 2013; Seamon and Zajonc, 1998). The archetypal ideas at work are manifold; they do provide a sense of reality, of certainty, but they interplay according to the context. This means that it would be inappropriate to state what is best practice for all situations. What we can do is build up a conceptual picture in connection with the phenomena we perceive, which helps to make meaning of one's own practice.

The following section explores the forms that water takes up in non-turbulent flow, their appearance and their lawfulness. In particular, it explores how water can be sensitive. This will provide us with some ideas with which to look at the practice of dynamisation.

\section{GEOMETRY AND GESTURES IN FLOW: SPIRAL AND RING VORTICES}

Geometry gives us the clarity of precisely defined concepts. In this chapter, I search for some commonality between these concepts and gestures in the study of flow. In our standard school Euclidian $^{1}$ geometry, concepts are generally fixed as rigid measurements, including distances and

${ }^{1}$ Euclid of Alexandria, Greek mathematician and founder of classical geometry, b.300 BC. 
angles. Projective geometry, developed mainly in the nineteenth and twentieth centuries, encompasses the Euclidian while also including the infinite, which is brought in from the far distance, such as through perspective drawings with vanishing points on the horizon line. This enables us to work with new spaces, in which the familiar Euclidian geometrical ideas are seen to be more restrictive cases of flexible thinking and universal ideas (Whicher, 2013).

Lawrence Edwards' work with projective geometry and natural form (2006) gives the defining geometrical idea of the spiral vortex in its pure form, which we see when water is being drawn towards a single distant point (under gravity this point is the earth's centre). We see this vortex every day as water goes down a plughole of a bath or sink. Edwards called this the watery vortex; I will call it the spiral vortex for reasons which will become clear later (see Figure 25.1). The geometry is what is known as a path-curve surface, composed of curved lines (Edwards, 2006). There are many such surfaces in natural forms, including eggs, buds, seed-bearing cones and the left ventricle of the heart. The lines are defined paths of movement in relation to four points, and one may choose any four points to create a path-curve. These points are named the invariant points and are unreachable or infinity points in terms of the movement.

In the case of the spiral vortex, shown in Figures 25.1 and 25.2, the lines of movement come from peripheral points in the infinitely distant line in the plane of the water surface, which may be easiest to think of as the horizon line, and they run to an infinitely distant point on the central axis. In the spiral vortex, unlike most path-curves, we can actually see the path of movement if we follow a suspended particle moving in the funnel surface. The movement runs spiralling down the funnel surface towards the infinitely distant point on the axis. For water flowing primarily under the draw of gravity, this axis tends to the vertical. Note that the spiral ripples that one sees in the photo do not show the path of movement, i.e. the flow, but are a structure in the flow, like standing waves in a stream.

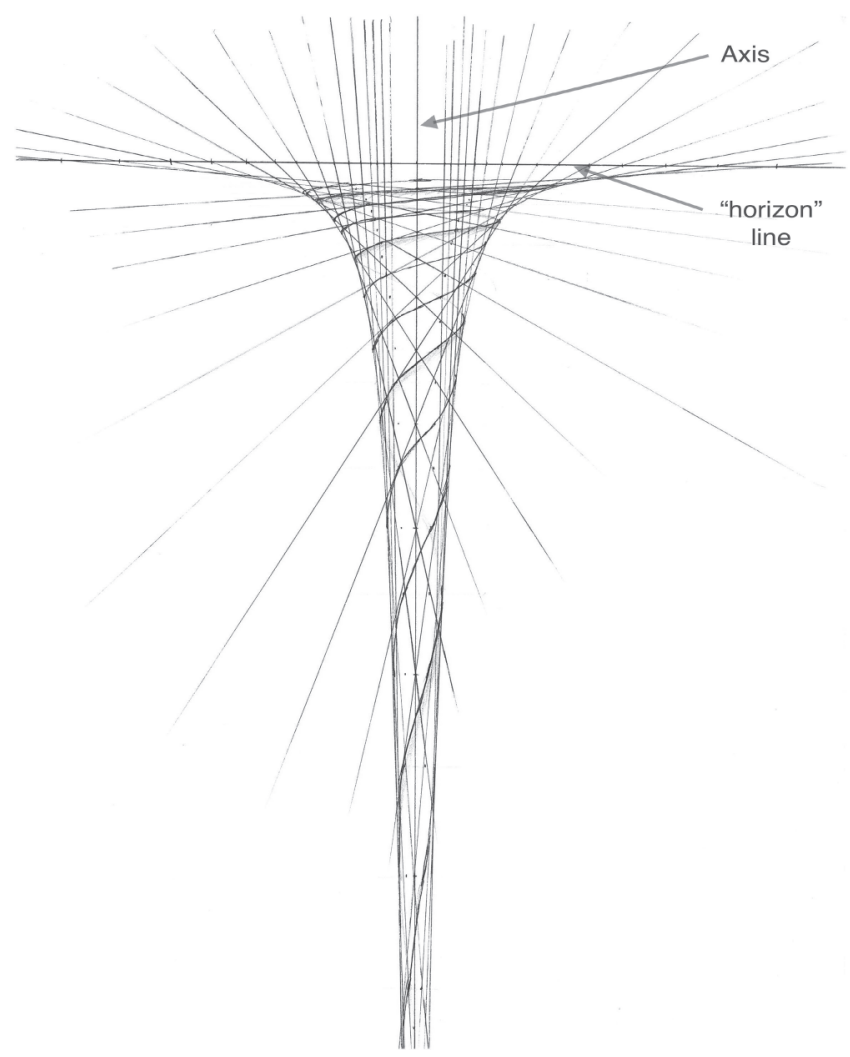

FIGURE 25.1 Spiral vortex geometry. (After Edwards, 2006.) 


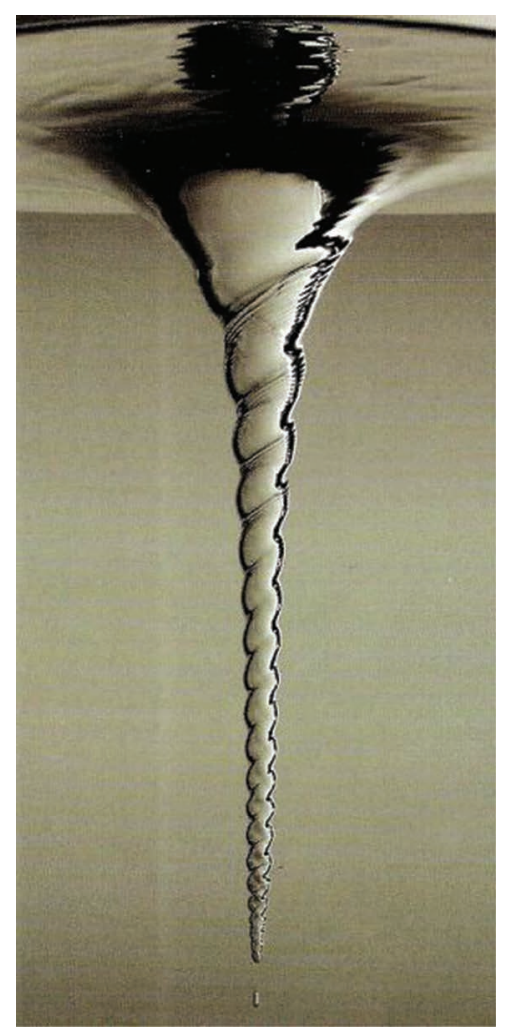

FIGURE 25.2 Spiral vortex. (Photo courtesy of Institute of Flow Science, Wilkens et al., 2005.)

Qualitatively, this vortex form can be experienced as very open, the surface stretching widely and also as having a contractive gesture, so that when we watch the form in flow, it draws suspended and floating matter towards the centre. It creates a concavity which, under the right conditions, can be many metres deep. This can be seen in Figure 25.3, both in the reflections on the surface and below it as the rope-like tube seen through the water.

This spiral vortex gesture is only part of the full picture. There is another form of fluid movement also called a vortex, the toroidal ring vortex. This is seen in air as smoke rings, often created by smokers and less often by volcanos. It can also be generated in water. It arises not when the fluid is being drawn under suction but when it is pushed, when it is under pressure from somewhere else. Figure 25.4 shows such a ring vortex.

This type of vortex can also be made quite easily in a still body of water by using a short discharge from a tube, as in Figure 25.5, which reveals both its form and its inherent layered structure.

The ring vortex also has a path-curve geometry, but with a transformed construction that embodies asymmetric spirals. These have been termed spiroids (Blackwood, 2012). Of significance here is that this ring vortex form does not have the same relation to the periphery; the movement relates to local, not peripheral, infinity points which are in the ring and on the axis. The movement in the form is more enclosing and relates more to itself, in that it rolls around its core. Qualitatively, we can experience it as having an expansive gesture, both when we observe its initial appearing (mushrooming out) and again at the end of its appearance when it meets resistance and deforms itself. It is very convex in its inherent surfaces. Thus, we can see the toroidal ring vortex, created with a push or a puff, as polar opposite in nature to the spiral vortex described above which was created with a draw or a suck. 


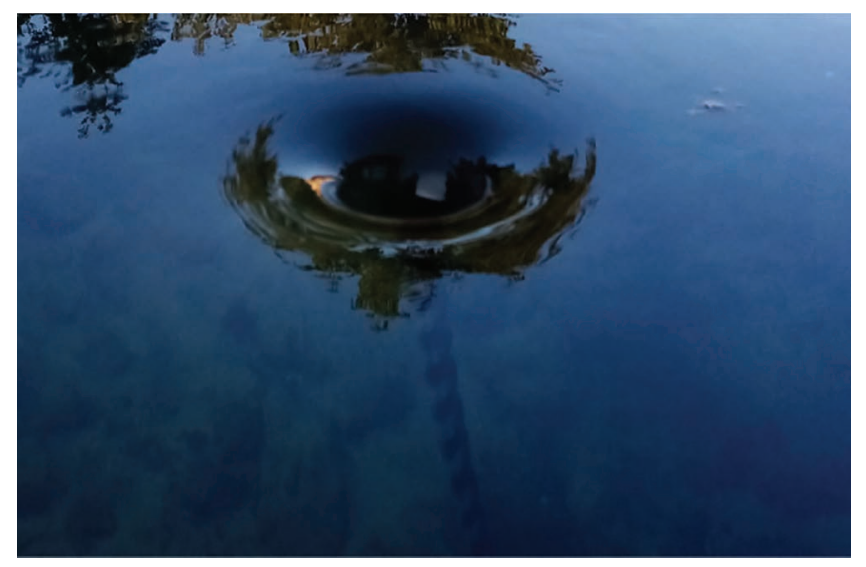

FIGURE 25.3 Spiral vortex in free water, viewed from above. (Photo credit: Simon Charter.)

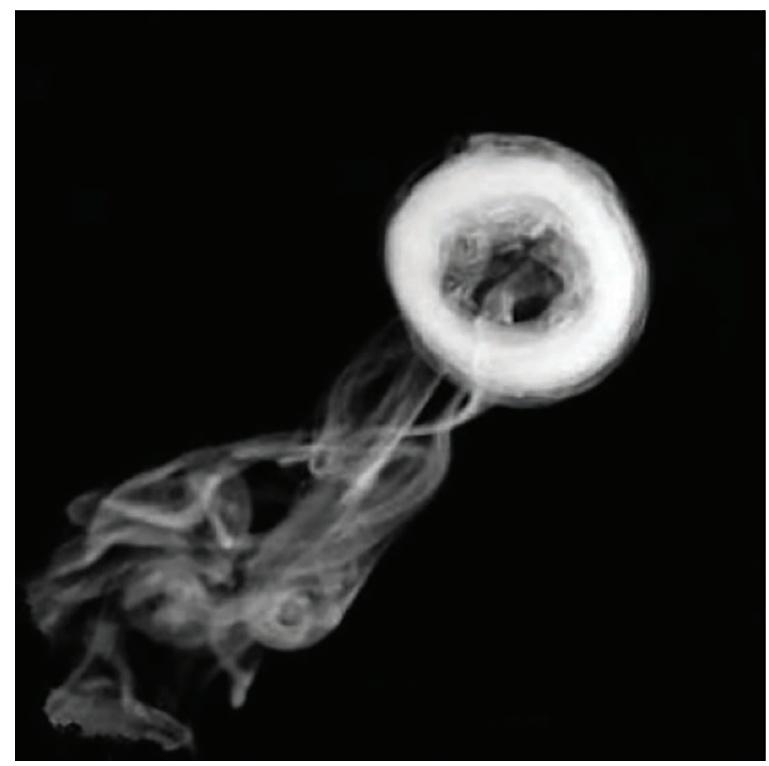

FIGURE 25.4 Ring vortex, smoke in air. (Photo credit: stock image from pinterest.com.)

Leonardo da Vinci, often seen as a forerunner of modern natural scientists, appears to have been aware of both these gestures. He made a close study of flow in water and is known to have used sawdust as a marker to observe the streaming of the liquid. He illustrated both of these gestures in a drawing (see Figure 25.6). The rings rising in the centre he called welling, and the spiral vortices around them he called eddying.

Da Vinci did not draw the way the surface looks, but rather his pen followed the paths of movement, and in doing, so he drew out the curved path of the water to find the gestures that the flow is making. For him, the drawing may have been a research methodology; he was looking for the lawfulness in nature as an aspect of the divinity (Kemp, referring to Leonardo's Codex Madrid II, 1989: 13). 


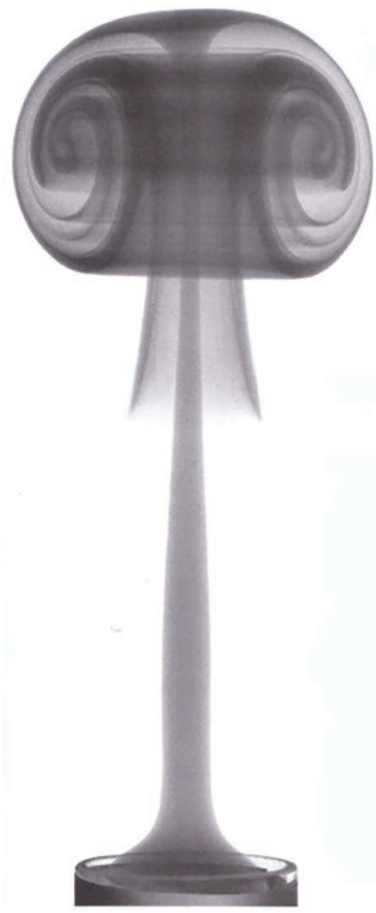

FIGURE 25.5 Ring vortex viewed from the side, made using marker dye in water, pushed in a slow pulse from the tube below. (Photo credit: by kind permission Andreas Wilkens, Institute of Flow Sciences, Herrischried, Germany, www.stroemungsinstitut.de.)

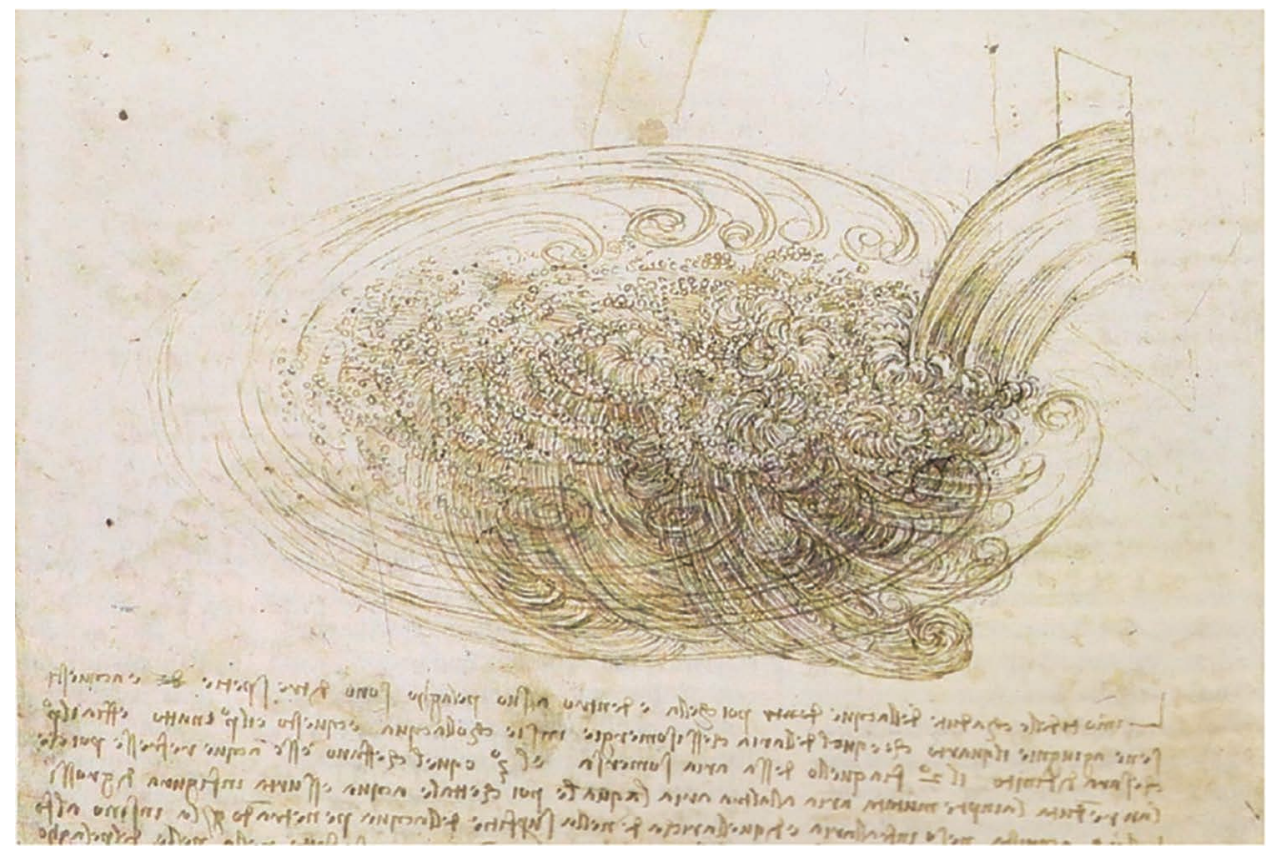

FIGURE 25.6 Water falling into a pool by Leonardo da Vinci, circa 1511. Original drawing held in the Royal Library Windsor (no 12660). (Reproduction courtesy Royal Collection Trust/@ Her Majesty Queen Elizabeth II 2020.) 
If one observes gently flowing water in a river with these two archetypal gestures in mind, one can see there is always a play between the two in the way it moves, with underwater obstructions pushing into the flow and expansive welling up occurring in front. Then behind an obstruction, little contracting eddies can be seen, associated with the drawing down of the water. The water, under push or draw, acts accordingly with either the expansive gesture (towards the ring vortex) or the contractive one (towards the spiral vortex).

In conclusion to this discussion of the phenomena, it is clear that that water is sensitive to the forces of pressure and suction. These are invisible forming forces of which we do have a direct experience.

\section{RHYTHM - ANOTHER GESTURE OF FLOW}

Neither of these two archetypal movement forms seem totally stable in the real world. The spiral vortex will often collapse in an expansive swelling out, especially when its connection to the source of the draw is disturbed, and when the ring vortex encounters resistance it can form a rhythmic pattern as it dissipates, as shown in Figure 25.7.

Another phenomena seen at the surface of a body of water is a marriage of the two vortex gestures, which is called the twin eddy or half-ring vortex (Cowern, 2014). It can be reproduced fairly easily at the surface of still water or on a gently moving water body, by dipping in a rounded flat paddle vertically, giving it a little push and pulling it out again. At each side of the paddle, we see what appears to be two separate spiral vortices (eddies), but a marker in the water (such as ink or milk) reveals their underwater linkage in a half-ring. Careful observation shows that its form also changes in a rhythmic way, and it oscillates slowly around a mean semicircular form. It is interesting that we have both pushed the water in front and pulled the water behind the paddle, and the result is a combination of both gestures. I call both this and the full-ring vortex 'movement organisms' as

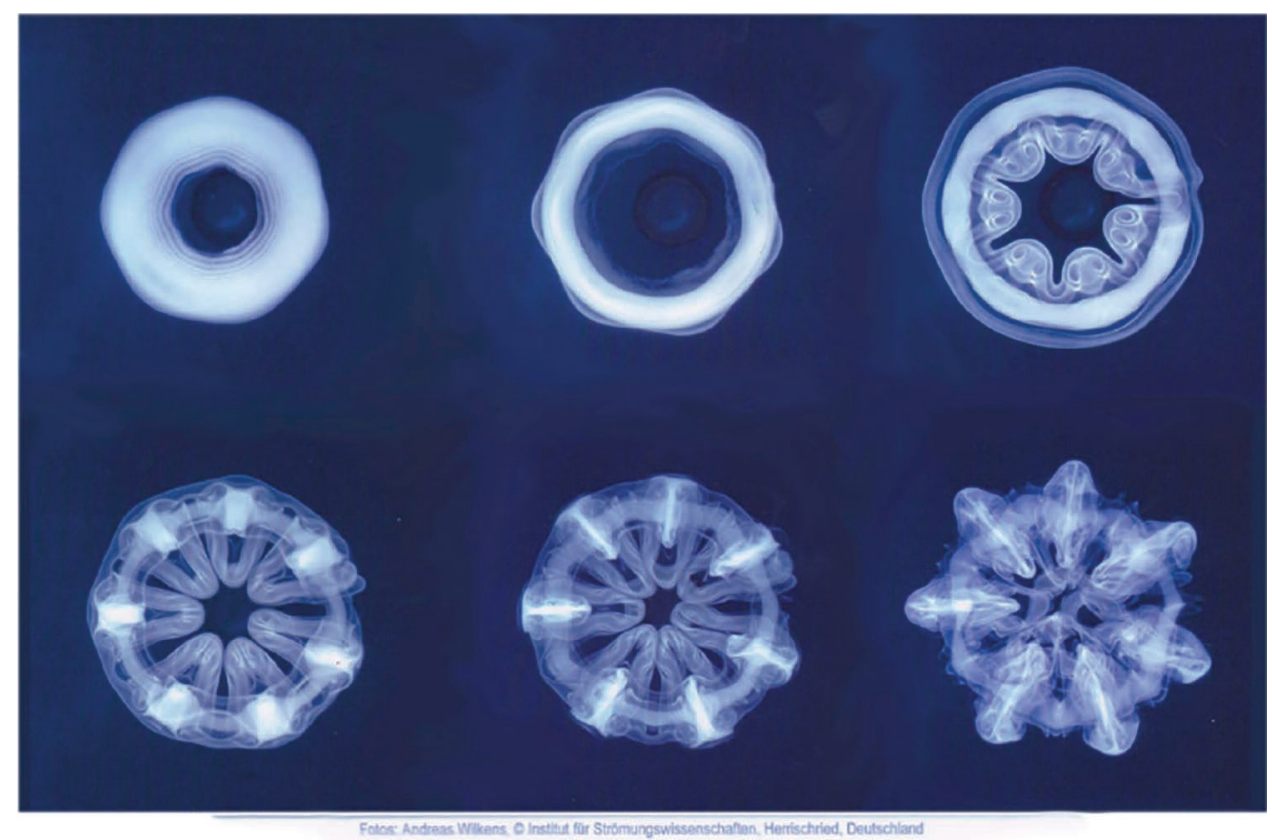

FIGURE 25.7 Collapsing ring vortex in water, seen end-on, as it slowly encounters a perpendicular glass wall. Top left shows the almost undisturbed toroidal ring, which changes through the forms to the bottom right where the form is beginning to disperse. (Photo credit: by kind permission of the Institute of Flow Science. Wilkens et al., 2005.) 
they have a 'birth', a rhythmic 'life' and eventually a 'death', a dissolution of the form. The spiral vortex might also be referred to in the same way, but its form extends into the whole body of fluid so it does not have the same self-maintaining, independent existence we usually associate with the term 'organism'.

If we introduce movement with a straight brushstroke through a suitable shallow layer of water, the brush pushes the water in front and draws in the water behind, and we see a wonderful rhythmic play involving the two polar movement gestures, as seen in Figure 25.8.

The phenomena appearing in Figure 25.8 is one of many rhythmic phenomena seen in fluid flow. There are the meanders, ripples and standing waves as seen in water but also in certain cloud formations. All of these can be seen as a play between the two polar gestures.

Illustrated here is the way that water in non-turbulent flow (also known as a harmonic laminar flow) has a tendency to form itself in a rhythmic play between the polar gestures of the two archetypal vortex forms, the spiral vortex and the ring vortex. I suggest therefore that there is actually a threefold archetype working in this flow, having an expansive pole, a contractive pole and a rhythmic aspect between these polar aspects.

I have tried to elucidate these three active forming ideas in water's laminar flow. The half-ring vortex shows to my mind that it is possible to see them as one transformable idea, so we might call this the archetypal gesture of water, just as Goethe saw the archetypal gesture of plant development in the transformable leaf idea (von Goethe, 2009). We will now see how this threefold gesture is present in dynamisation.

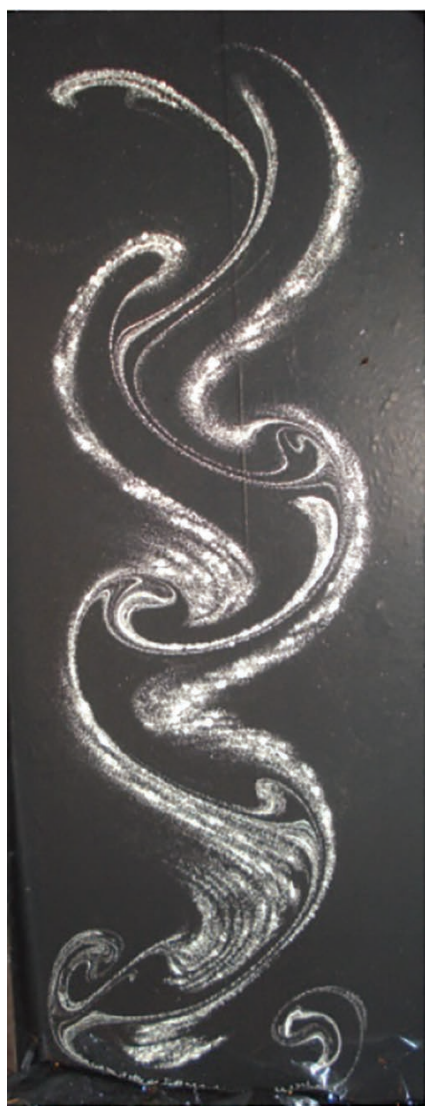

FIGURE 25.8 Rhythmic pattern of alternating vortices (also known as the Kármán vortex street). (Photo credit: Simon Charter.) 


\section{THE DYNAMISATION OF WATER}

Through studying the unfolding of life forms in the way proposed by Goethe, one can see particular species-specific forming influences and one can also see archetypal form gestures. These both work in a coherent way within the constraints of each spatial and temporal situation, such that we can recognise a specimen of a given species at all stages of its development. For instance, a nettle seedling with only two leaves can be recognised as the same species as an older specimen in full flower. In its growth, each organism can be seen to strive towards its specific, qualitatively recognisable form, but this is a fluid form which has a temporal dimension to it. There is no final, fixed form (blueprint or template) imprinted onto the organism in a mechanical way. Methods of achieving such an understanding of natural form are well described by Hoffman (2007), and Colquhoun and Ewald (1996). The observation of the forms of the "movement organisms' in fluid flow, as previously described, can help us to grasp this aspect of life. These forming influences belong to the whole, and they permeate all the parts. In biodynamic agriculture, they are thought to originate in the peripheral entities of the moon, the planets and the stars (Daath, 2006; Thornton Smith, 2009). This is supported by a body of evidence for the effect of the moon on living organisms (e.g. Barlow, 2012; Endres and Shad, 2002), as well as by extensive correlation of tree-bud shape changes with planetary alignments (Edwards, 2006: 213-248). Working with these cosmic influences has shown positive results for many farmers and gardeners (Thun, 2003). When seeking to develop healthier plant life, one works to strengthen the working of such cosmic influences. To do this, one can choose appropriate planting and sowing times according to the positions of planets, and one can also apply biodynamic preparations which are carefully prepared, natural materials that bring specific benefits to the growing plants (von Wistingshausen et al., 2000).

These are enhanced through the mediation of water. One can work with movements in the water to both open the water to be sensitive and then to hold these influences within the water. One way to do this is through dynamisation, which can involve stirring up a container of water, by hand or by another mechanism. Before applying the biodynamic preparations, they are mixed in water in a barrel and stirred in a particular way, usually for an hour. A vortex is created and then broken, and then created again. The vortex opens out the surface and draws the funnel form down into the depth of the barrel which can be experienced as a contractive gesture. To break this form, one must exert pressure against the flow; the resulting movements are more chaotic and expansive but can be experienced as closing in the flow. The water is then stirred in the opposite direction to establish a vortex again, and this is then broken again. This is repeated continuously. The rhythmic stirring movement is not a simple repetition but a varying rhythm as it is in the heartbeat, in breathing and in other rhythmic functions of living organisms. The human being is present, with his/her consciousness accompanying the stirring process.

This dynamisation of the biodynamic preparation may be seen to embody the rhythmic play between the two movement gestures we have identified already: a contractive, well-formed gesture open to the surroundings (reaching out to the periphery) and an expansive, more chaotic gesture closing up within itself. This qualitative exploration of the flow can help us begin to see why dynamisation was originally indicated by Rudolf Steiner as a life-supporting process (Steiner, 2004), and why many farmers continue the practice (von Wistingshausen et al., 2000).

The biodynamic preparations are usually applied to the whole farm or garden rather than one part, and this reflects the holistic approach inherent in biodynamics (Osthaus, 2010). Such dynamised liquid stimulates particular processes in the soil and plant life, for instance the vegetative growth, the flowering or the fruit ripening process (Thun, 2003). If we think of dynamisation as the establishment of a movement organism in the water body, which has a spatial form and is also formed in time, this may indicate why the dynamised liquid may be resonant with forces for only a limited time period and needs to be applied soon after stirring has finished. For preparations to be used over large areas, dynamisation has been undertaken by machine, stirring with a motor and 
suitable gearings, but this will have a more mechanical rhythm. Since the 1980s, dynamisation has also been undertaken in various countries using Flowform water sculptures. We will now look into what happens in this method of engendering movement in water.

\section{FLOWFORM MOVEMENT: AN ALTERNATIVE METHOD OF DYNAMISATION}

Flowforms are vessels specifically designed for water to embody rhythmic flow patterns. They are usually designed in clay with water flowing through them in an interactive way. The potential for such resonant water movements was discovered by John Wilkes while working with Theodor Schwenk in 1970 (Wilkes, 2003). They have been used for dynamisation among many other uses.

When water flows into a Flowform water sculpture (see Figure 25.9), it is channelled into a bowl where it meets resistance before it can flow out. If the space is appropriately formed and if the resistance at the outflow is not too much or too little for the incoming velocity of flow, then some water builds up in the bowl to meet the inflow, and the movement becomes unstable. The conditions for this instability are essential as the water needs to meet itself in a free and conducive space, and it is often seen to move in an unpredictable way until a resonant recurrent flow pattern asserts itself. In this way, the water is able to establish a stable rhythmic flow condition. When this first happens in a Flowform, the strength and vigour of the movement build up and one feels it 'come to life'. The water reaches up further and reaches out further than previously. Even though it has an average frequency and reach, the rhythmic flow varies, just as a healthy human heart also has variability in its beat even while at rest (Campos, 2017).

The flow pattern in the Flowform vessel can be characterised in many ways; it can be regarded as a wave moving around the vessel, and in some designs, the wave moves in a clearly defined lemniscate. This 'figure of 8 ' form can also be seen as the path of an imagined particle in the water. In contrast to this observation of a part, we can try to observe and experience the movement of the whole body of water. We can then experience the water in a play between the rising expansive gesture (or the beginnings of it), as the water is being pushed up in one side of the vessel, and the contracting spiralling gesture (or the beginnings of it) as it is drawn out. The forms can also be seen to embody rhythm as expressed in all living organisms, an alternating play of expansion and contraction (Figure 25.10).

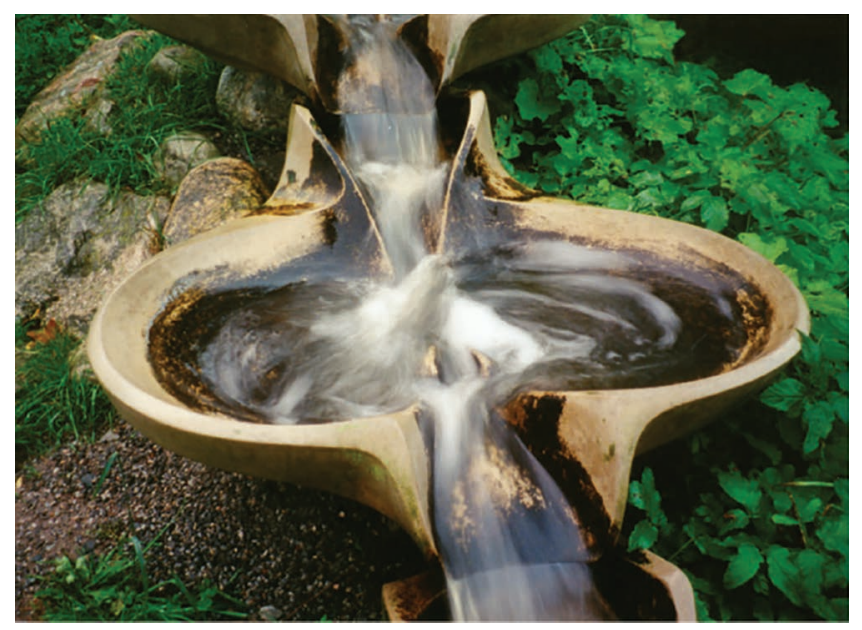

FIGURE 25.9 'Malmo' Flowform Design by John Wilkes, Nigel Wells and Nick Weidmann. (Photo credit: Imke Naudascher.) 


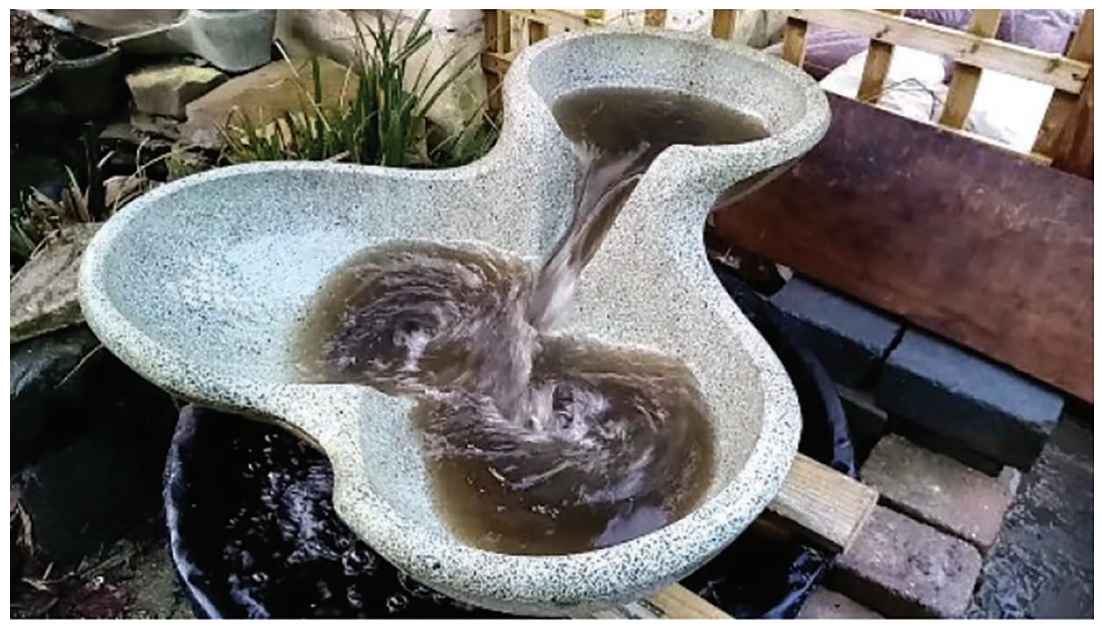

FIGURE 25.10 'Vortex’ Flowform Design, by John Wilkes, Nick Weidmann and Michael Monzies. (Photo credit: Simon Charter.)

Thus, the flow pattern can also be seen as having the same gestures of dynamisation as when done by hand in a barrel. However, Flowforms embody these principles in a variety of ways according to their design, and different types may be chosen to suit different purposes.

In agriculture, Flowforms have also been used to dynamise irrigation water. Based on my experiences and reports from others, this can result in statistically significant crop improvements (both quantitative and qualitative) over controls. However, as these results are seldom repeatable, they have not generally been published. This does, however, suggest that a non-mechanistic process is at work. For example, in 2004, a trial was performed with lettuce whereby the irrigation water was dynamised with Flowforms (Schwuckow et al., 2010: 77-83). Significant increases in total plant weight of between $25 \%$ and $32 \%$ over the control, as well as improvements in colour, form and flavour, were found. However, the following year, a more extensive trial with more crops showed no significant differences. A horticulturalist involved in the second trial was still convinced of improvements in overall crop health and especially initial root growth and went to great lengths to dynamise all his greenhouse irrigation water over future seasons. He and I both observed that his crops became crisper in form and texture and less susceptible to mould.

Another application of moving water in agriculture is in the production and use of aerated compost tea, and studies show the benefits of using this as a liquid nutrient fertiliser in a variety of crops (Min et al., 2015). A comparative trial of the performance of Flowforms compared to mechanical aeration has been undertaken in a soil-food-web laboratory on a biodynamic farm in the UK. The comparison was between aeration using an air pump that pushed bubbles into the liquid, and a Flowform cascade. With the Flowform, dissolved oxygen levels were higher for many days after aeration had ceased, but in the case of the air pump, as soon as the device was turned off, the oxygen levels dropped to the base level (Personal Communication, J. Williams, November 2017). More systematic research is required.

\section{HOMEOPATHIC POTENTISATION}

A final, but important, rhythmic process that is distinct from dynamisation but also done with water is homeopathic potentisation. Here, a specifically chosen substance is diluted repeatedly, as well as subjected to rhythmic movements (succussion) between dilutions. The method of succussion as originally advocated by Samuel Hahnemann - the father of homeopathy - involves raising the bottle of remedy and thumping it down on a thick book or similar soft but solid surface. For the water, this 
technique involves a rhythmic play of more pressure (on the thump down) and less pressure (when lifted up). This is done in order to create a remedy, which can have specific healing effects on an organism, usually human or animal. It can also be used for a crop or a whole farm or garden ecology.

According to homeopathic practice, this potentisation process provides a more time-stable remedy whose influence can be brought into play in an organism many years after it has been made, and for this reason, remedies are not usually given a shelf life. Homeopathy in agriculture is a fast-developing area of research and practice in both India and South America (Sen et al., 2018), and some dramatic results have been achieved with certain plant illnesses (Kaviraj, 2012).

\section{CONCLUDING DISCUSSION: RESEARCH WITH THE LIFE-FORMING FORCES}

When researching with living organisms and subtle influences, one factor is seldom taken into account: the influence of the researcher on the research. In my experience over the last 30 years, experiments in this field that attempt to establish reproducibility and to prove a cause and effect in a reductionist way invariably fail. Often then the work is not published. French immunologist Jaques Benveniste was famously dogged by this issue of reproducibility after sceptics questioned the results of his research into high dilution effects on living tissue which he had published in the journal Nature (Davenas et al., 1988). Eventually, Benveniste found that reproducible results were possible for certain experimenters and not others. Experiments undertaken robotically also failed, unless a connection with an effective experimenter was established, and this was undertaken through using a sample of water (Personal Communication, J. Benveniste, December 1998).

Most subtle forming influences in living things are not physical or chemical in origin, but they can still be grasped clearly. These organising principles in life, these active ideas, can be considered aspects of the spiritual working in the physical world. If the influenced phenomena were predictable in a mechanistic way, we would feel obliged to take up a subservient position in relationship to this spiritual realm and become mechanistic in our own dealings with the living world. This would run counter to our ability to be free and independent, to work out of our own sense of responsibility in any given situation and to seek what we find to be true, beautiful and good. The more we get to know the qualities of these active influences at work in the natural world, the more these influences also become creative, artistic tendencies in us, and we willingly work in tune with them.

Many influences in the environment are working on plants, yet overarching these are subtle forming forces that may be mediated by the water in and around the organism. These work as a whole on the whole plant and involve the surrounding rocks, plants, animals, humans and astronomical events. Based on my work with water, there seem to be forces working both from within outward and from the periphery inward, and these work to achieve the time-variable but characteristic form of the organism.

The scientific challenge is to be open to these subtle factors and also to become clearer as to what is going on with both the sense-perceptible world and ideas working in the perceived phenomena (i.e. natural laws and identifiable gestures). We are looking for the satisfying marriage of percept and concept, of phenomena and idea. If we can educate ourselves to read the ideas within what we perceive, then the meaning of the workings of the natural world can increasingly unfold. One of the roles of water claimed by Theodor Schwenk is that it can help us to read this world of living beings. Through observation of its fluidity, 'our way of thinking becomes changed and more suited to the understanding of what is alive' (2014: 11). This need is far greater now than when Schwenk originally suggested this in 1961, and it may be an essential step if we wish to free ourselves from trying to manipulate nature and learn to work and play responsibly with her.

\section{REFERENCES}

Barlow, P.W. (2012) Moon and cosmos: Plant growth and plant bioelectricity. In Volkov, A. (ed), Plant Electrophysiology. Berlin/Heidelberg: Springer, pp. 249-280. 
Bateson, G. (2002) Mind and Nature, a Necessary Unity. Cresskill, NJ: Hampton Press.

Blackwood, J. (2012) Geometry in Nature. Edinburgh: Floris Books, pp. 87-89.

Bortoft, H. (1996) The Wholeness of Nature. Edinburgh: Lindisfarne Books/Floris Books.

Bortoft, H. (2012) Taking Appearance Seriously. Edinburgh: Floris Books.

Campos, M. (2017) Heart rate variability, a new way to track wellbeing. Harvard Health Blog. https:// www.health.harvard.edu/blog/heart-rate-variability-new-way-track-well-2017112212789 (accessed September 10th, 2020).

Colquhoun, M. and Ewald, A. (1996) New Eyes for Plants, a Workbook for Observing and Drawing Plants. Stroud: Hawthorn Press.

Cowern, D. (2014) Fun with vortex rings in the pool. Physics Girl. https://www.youtube.com/ watch? $\mathrm{v}=72 \mathrm{LWr} 7 \mathrm{BU} 8 \mathrm{Ao} \& \mathrm{t}=1 \mathrm{~s}$ (accessed September 11th 2020).

Daath, H. (2006) The Biodynamic Action of Planets. Whitefish, MI: Kessinger Publishing.

Danek, A.H. and Salvi, C. (2020) Moment of truth: Why Aha! Experiences are correct. Journal of Creative Behaviour, 54(2):484-448.

Davenas, E., Beauvais, F., Amara, J., Oberbaum, M., Robinzon, B., Miadonna, A., Tedeschi, A., Pomeranz, B., Fortner, P., Belon, P., Sainte-Laudy, J., Poitevin, B. and Benveniste, J. (1988) Human basophil degranulation triggered by very dilute antiserum against IgE. Nature 333:816-818.

Edwards, L. (2006) The Vortex of Life. Edinburgh: Floris Books.

Endres, K.-P. and Shad, W. (2002) Moon Rhythms in Nature, How Lunar Cycles Affect Living Organisms. Edinburgh: Floris Books.

Hoffman, N. (2007) Goethe's Science of Living Form: The Artistic Stages. Hillsdale, MI and New York: Adonis Press.

Holdrege, C. (2013) Thinking Like a Plant, a Living Science for Life. Great Barrington, MA: Lindisfarne Books.

Kaviraj, V.D. (2012) Homeopathy for Farm and Garden: Homeopathic Treatment of Plants. Kandern: Narayana Verlag.

Kemp, M. (1989) The Disciple of Experience, Leonardo da Vinci. London: Yale University Press for The South Bank Centre.

Min, J.K., Chang, K.S., Yong, K.K., Sung, J.H., Jong, H.P., Eun, J.H., Jin, H.K. and Suk, C.K. (2015) Effect of aerated compost tea on the growth promotion of lettuce, soybean, and sweet corn in organic cultivation. Plant Pathology Journal, 31(3):259-268.

Osthaus, K.E. (2010) The Biodynamic Farm, Developing a Holistic Organism. Edinburgh: Floris Books.

Schwenk, T. (2014) Sensitive Chaos, the Creation of Flowing Forms in Water and Air. Forest Row: Sophia Books.

Schwuckow, J., Wilkes, J. and Trousdell, I. (2010) Energizing Water, Flowform Technology and the Power of Water. Forest Row: Sophia Books.

Seamon, D. and Zajonc, A. (1998) Goethe's Way of Science, a Phenomenology of Nature. New York: SUNY Press.

Sen, S., Chandra, I., Khatun, A., Chaterjee, S. and Das, S. (2018) Agrohomeopathy, an emerging field of agriculture for higher crop productivity and protection of plants against various stress conditions. IJRAR, 5(4):52-56.

Steiner, R. (1988) Goethean Science. Rochester, NY: Mercury Press.

Steiner, R. (2004) Agriculture. Forest Row: Rudolf Steiner Press.

Thornton Smith, R. (2009) Cosmos, Earth and Nutrition, the Biodynamic Approach to Agriculture. Forest Row: Rudolf Steiner Press.

Thun, M. (2003) Results from the Biodynamic Sowing and Planting Calendar. Edinburgh: Floris Books.

von Goethe, J.W. (2009) The Metamorphosis of the Plant. Cambridge, MA: MIT Press.

von Wistingshausen, C., Scheibe, W. and König, U.J. (2000) The Biodynamic Spray and Compost Preparations Production Methods. Stroud: Biodynamic Agricultural Association.

Whicher, O. (2013) Projective Geometry, Creative Polarities in Space and Time. Forest Row: Sophia Books.

Wilkens, A., Schwenk, W. and Jacobi, M. (2005) Understanding Water: Developments from the Work of Theodor Schwenk. Edinburgh: Floris Books.

Wilkes, A.J. (2003) Flowforms: The Rhythmic Power of Water. Edinburgh: Floris Books. 